\title{
Perencanaan Jaringan Komunikasi Antara Patani Dan Sorong Menggunakan Radio Microwave
}

\author{
Nurwendah Puspita, Rianto Nugroho \\ Program Studi Teknik Elektro, Fakultas Teknik dan Sains, Universitas Nasional \\ Korespondensi : riantnugroho@yahoo.com
}

\begin{abstract}
ABSTRAK. Pembangunan jaringan telekomunikasi antara pulau Maluku - Papua menggunakan radio microwave dengan teknologi SDH (Synchronous Digital Hierarchy) yang dapat memenuhi kapasitas yang besar dan kehandalan yang cukup tinggi. Pemilihan komunikasi dengan radio microwave pada link ini disebabkan banyaknya kendala pada proses implementasinya, dimana link ini melewati lautan, oleh sebab itu tidak memungkinkan membangun komunikasi kabel laut dalam waktu relatif singkat. Maka sistem komuikasi radio microwave memberikan suatu solusi. Sistem ini merambat dalam garis pandang (line of sight) atau ruang bebas sehingga tidak diperlukan syarat utama yang harus dipenuhi dalam membangun komunikasi radio microwave. Sebelum membangun sistem komunikasi radio microwave maka dibutuhkan perencanaan agar sistem ini memenuhi kebutuhan suatu sistem komunikasi. Perencanaan dilakukan terdiri atas beberapa tahap seperti penentuan lokasi, penentuan rute radio link, konfigurasi radio link dan path analisys. Tahap-tahap tersebut dilaksanakan agar mendapatkan hasil yang maksimal pada suatu perencanaan. Hasil perencanaan dapat digunakan sebagai referensi penentuan penggunaan perangkat yang sesuai dengan spesifikasi dalam pembangunan komunikasi radio microwave dengan rute pulau Maluku - Papua agar mendapatkan hasil yang sesuai dengan standarisasi internasional. Dalam hal ini standar yang digunakan mengacu pada ITU-R
\end{abstract}

Kata kunci : SDH (synchronous digital hierarchy), radio microwave

\begin{abstract}
Telecommunication network development between Maluku island - Papua island using radio microwave with SDH (Synchronous Digital Hierarchy) Technology can be solution for the big capacity and high performance. Choosing communication using radio microwave for link because a lot of constraint at process implementation, which one this link pass the ocean and than that impossible build cable on the ocean in the quick time, and radio microwave become solution for this issue. This system creep at Line of Sight or Free Space Lost and so we no need physical line are like cable. LOS condition becomes the first condition if we want to build the microwave communication. Before build the system radio microwave communication we need planning, that is location determination, Radio Link route, Radio link configuration and path analysis. That is maximum result. The planning result can be use as reference for equipment match with specification, on the built communication, Radio microwave with route Maluku island - Papua island getting result according to international standardization that is ITU-R.
\end{abstract}

Keywords : SDH (synchronous digital hierarchy), radio microwave.

\section{PENDAHULUAN}

Patani dan Sorong merupakan pulau yang terletak di bagian Utara Pulau Maluku dan Barat Pulau Papua. Kedua pulau tersebut dipisahkan oleh selat. Karena kebutuhan telekomunikasi pada area tersebut sangat tinggi maka diperlukan suatu sistem komunikasi yang dapat melewati perairan. Sistem komunikasi yang dipilih adalah menggunakan sistem komunikasi radio gelombang microwave dengan media transmisi udara. Sistem komunikasi radio gelombang microwave dipillih karena dapat melayani beberapa ribu saluran suara (voice) dengan tingkat kehandalan yang cukup tinggi serta jarak tempuh yang lebih efisien karena melewati media transmisi udara. Dalam studi perencanaan jaringan komunikasi di wilayah Patani - Sorong. Perencanaan jaringan komunikasi ini akan disesuaikan dengan karakteristik pulau Maluku Utara dan Papua Barat. 


\section{PARAMETER KINERJA SISTEM KOMUNIKASI}

Sistem komunikasi dengan microwave sekarang beroperasi dengan modulasi QAM (Quadrature Amplitudo Modulation). Unjuk kerja dari komunikasi digital ini diukur dalam BER (Bite Error Rate). Level daya ambang batas untuk peralatan transceiver sering didefinisikan dimana BER (Bite Error Rate) mencapai $10^{-6}$ walupun nilai BER yang lain dapat diterima. Nilai tersebut menjadi parameter peralatan receiver. Microwave bekerja pada rentang Frekuensi $2 \mathrm{GHz}-23$ GHz. Gelombang radio dari pemancar merambat menurut arah garis lurus. Ketika daya bergerak menjauhi sumber radiator isotropis, daya rata-rata $(P r)$ terpancar sama kesemua arah dan akan menyebar dalam bentuk bola, sehingga pada jarak $(d)$, kerapatan daya pada gelombang yang ada adalah daya persatuan luas permukaan gelombang yaitu ;

$$
P_{D i}=\frac{P_{r}}{4 \lambda \cdot d^{2}} \quad w / m^{2}
$$

dimana :

$$
\begin{aligned}
& P_{D i}: \text { kecepatan daya isotropik } \\
& \operatorname{Pr}: \text { daya rata-rata } \\
& d: \text { jarak }
\end{aligned}
$$

Perolehan keterarahan (Directivity Gain) antena adalah perbandingan dari kerapatan daya yang sesungguhnya pada sumbu utama dari radiasi antena. Perolehan keterarahan maksimum $(G r)$ dari antena pemancar dan kerapatan daya di sepanjang arah dengan radiasi maksimum adalah :

$$
P_{D}=P_{D i} \cdot G_{T}=\frac{P_{r}}{4 \lambda \cdot d^{2}} G_{T}
$$

dimana :

$$
G_{T}: \text { Perolehan keterarahan maksimum }
$$

Koordinat lokasi dibutuhkan untuk menentukan beberapa parameter jarak antara dua titik, posisi, azimut dan kontur permukaan bumi yang akan dilalui oleh lintasan gelombang radio. Dengan bantuan peta berskala yang dilengkapi dengan garis-garis koordinat dan garis kontur permukaan bumi. Koordinat lokasi diperoleh dengan menentukan titik pada kontur bumi berupa posisi titik tersebut pada garis Lintang dan garis Bujur.

Path profile (Peta Penampang) dengan metode flat earth curve adalah alat bantu berupa grafik berskala yang dipergunakan untuk menentukan kondisi lintasan memenuhi syarat LOS atau tidak $L O S$ dengan proyeksi permukaan bumi datar. Parameter yang harus diperhatikan dalam penggambarannya adalah daerah fresnell, tinggi obstacle sepanjang lintasan, koreksi ketinggian tiap obstacle di sepanjang lintasan, high clearence dan jarak.

Daerah fresnell adalah tempat kedudukan titik-titik sinyal tak langsung (berbentuk ellips) dalam lintasan gelombang radio, dimana daerah tersebut dibatasi oleh gelombang tak langsung yang mempunyai beda panjang lintasan dengan sinyal langsung, seperti rumus dibawah ini :

$$
F 1=17,3 \sqrt{\frac{d 1 \cdot d 2}{f . d} m}
$$

dimana :

$$
\begin{aligned}
& f: \text { frekuensi }(\mathrm{GHz}) \\
& d: \text { jarak lintasan }(\mathrm{Km}) \\
& d 1 \& \text { d : jarak }(\mathrm{Km}) \text { dari terminal ke lintasan obstacle }
\end{aligned}
$$

Parameter berin=kutnya adalah koreksi ketinggian, koreksi ketinggian diperlukan karena penggambaran terhadap kondisi bumi yang terbentuk bulat, hal ini memberikan pengaruh terhadap tinggi obstacle pada sepanjang lintasan sistem telekomunikasi gelombang radio mikro, seperti persamaan dibawah ini : 
dimana :

$$
h_{k}=\frac{d_{1} \cdot d_{2}}{12,75 \mathrm{x} \mathrm{K}} m
$$

$\begin{array}{ll}h_{\mathrm{k}} & \text { : koreksi ketinggian }(m) \text { terhadap permukaan laut } \\ \mathrm{K} & : \text { faktor kelengkungan bumi (konstanta) } \\ d 1 \& d 2 & : \text { jarak }(\mathrm{Km}) \text { dari terminal ke lintasan obstacle }\end{array}$

Parameter berikutnya adalah high clerence yaitu jarak antara sumbu utama lintasan gelombang radio dengan puncak penghalang (obstacle). Agar syarat Line Of Sight (LOS) terpenuhi maka besarnya tinggi obstacle harus dperhitungkan pada titik dimana terletak obstacle yang tertinggi, yaitu :

$$
h_{c}=\frac{h_{1} \cdot d_{2}+h_{2} \cdot d_{1}}{d}-h_{k-} h_{s}
$$

dimana :

$h_{c}$ : ketinggian obstacle $(\mathrm{m})$ terhadap permukaan laut

$h_{1}$ : ketinggian antena $1(\mathrm{~m})$ terhadap permukaan laut

$h_{2}$ : ketinggian antena $2(m)$ terhadap permukaan laut

$h_{k}$ : koreksi ketinggian $(m)$ terhadap permukaan laut

$h_{s}$ : ketinggian obstacle $(m)$ terhadap permukaan laut

$d 1 \& d 2:$ jarak $(\mathrm{Km})$ dari terminal ke lintasan obstacle

Power Link Budget atau yang disebut juga level daya terima nominal (Receive Signal Level) sistem transmisi dapat dihitung dengan persamaan berikut :

$$
R S L=P_{\mathrm{t}}+\mathrm{G}_{\text {total }}+L_{\text {trasmisi }}
$$

dimana :

$R S L$ : level daya terima $(\mathrm{dBm})$

$P_{\mathrm{t}}$ : Daya Transmisi $(\mathrm{dBm})$

$\mathrm{G}_{\text {total }}$ : Gain Total Antena Rx dan Tx $(d B)$

$\mathrm{L}_{\text {tra }}$ : Redaman Transmisi $(d B)$

\section{Frequency Selective Fading}

Fading adalah variasi sinyal terima saat sebagai fungsi dari fasa, polarisasi dan kuatnya sinyal terima akibat pengaruh hambatan lintasan baik itu pembiasan, pemantulan, difraksi, hamburan, redaman dan karena akibat-akibat yang lain. Sedangkan flat fading mempunyai karakteristik dimana level sinyal naik turun dengan lambat, hal ini menyebabkan putusnya hubungan yang lama. Flat fading terjadi akibat pembelokan beam yang di sebabkan oleh perubahan indeks bias atmosfer. Pada kondisi standar faktor $K=4 / 3$. Kondisi super refraksi $K>4 / 3$ menyebabkan beam membelok ke bawah. Pembelokan ini akan menyebabkan gelombang akan terpantul oleh permukaan bumi, sehingga akan membentuk lintasan lain selain lintasan gelombang langsung.

Beikutnya adalaha Fading Margin yaitu perbedaan antara level sinyal terima nominal dengan level sinyal terima minimum (threshold), yang sesuai dengan bit error rate (BER) yang diinginkan. Flat Fading Margin (FFM) dihitung untuk mengatasi error yang disebabkan thermal noise. Dihitung dengan rumus sebagai berikut :

$$
F F M=R S L-R x_{(\text {threshold) }}
$$

dimana :

FFM : Flat Fading Margin

$R S$ : level daya terima $(\mathrm{dBm})$

$R x_{\text {(hreshold }}$ level threshold dari thermal noise penerima $(\mathrm{dBm})$

\section{Probabilitas Outage}

Probabilitas outage adalah kemungkinan putusnya suatu hubungan komunikasi. Probabilitas outage perlu diperhitungkan dalam perancangan sistem gelombang mikro karena diperlukan 
untuk mengestimasi kondisi terburuk atau dalam kondisi fading terburuk agar komunikasi tidak terputus. Pada transmisi gelombang mikro, outage disebabkan oleh distorsi gelombang akibat Frequency Selective Fading, interferensi dan noise thermal. Rekomendasi ITU-R 633-3 menetapkan propagasi outage dengan panjang lintasan $2500 \mathrm{Km}$ dan maksimum 9 hop, untuk $280 \leq L \leq 2500 \mathrm{Km}$ yaitu $P_{t} \leq 0,000448$

Availability sistem radio diatur oleh rekomendasi ITU-R F634-3, dimana untuk sistem radio dengan panjang lintasan $\leq 280 \mathrm{Km}$ adalah $A V \geq 0,999252$

\section{Probabilitas Outage untuk Sistem Tanpa Menggunakan Teknik Diversity}

Berdasarkan rekomendasi ITU-R P.530-8 untuk menghitung probabilitas outage total sistem adalah sebagai berikut :

$$
P t=P_{n s}+P_{s}+P_{x p}
$$

dimana :

$P_{n s} \quad$ : probabilitas outage disebabkan non-selective fading

$P_{s} \quad$ : probabilitas outage disebabkan selective fading

$P_{x p} \quad$ : probabilitas outage disebabkan $x p$ degradasi

\section{Probabilitas Outage untuk Sistem Menggunakan Teknik Diversitas}

Teknik diversitas adalah suatu teknik dimana memiliki penerimaan rangkap. Adapun teknik yang digunakan adalah teknik space diversity. Penggunaannya saat kasus radio link memiliki jarak yang jauh dan untuk menghindari multipath fading. Harga total probabilitas outage menggunakan teknik diversitas dihitung dengan persamaan :

$$
P_{t}=P_{d} x P_{x p}
$$

dimana :

$P_{d}$ : kombinasi probabilitas outage disebabkan oleh selective dan non selective

\section{PERENCANAAN JARINGAN TRANSMISI}

\section{Penentuan Lokasi dan Route Radio Link}

Peta rute dibuat untuk melihat jalur yang akan digunakan untuk jaringan radio microwave dan juga melihat kondisi geografisnya secara umum. Lokasi yang akan dijadikan stasiun berjumlah 5 Site.

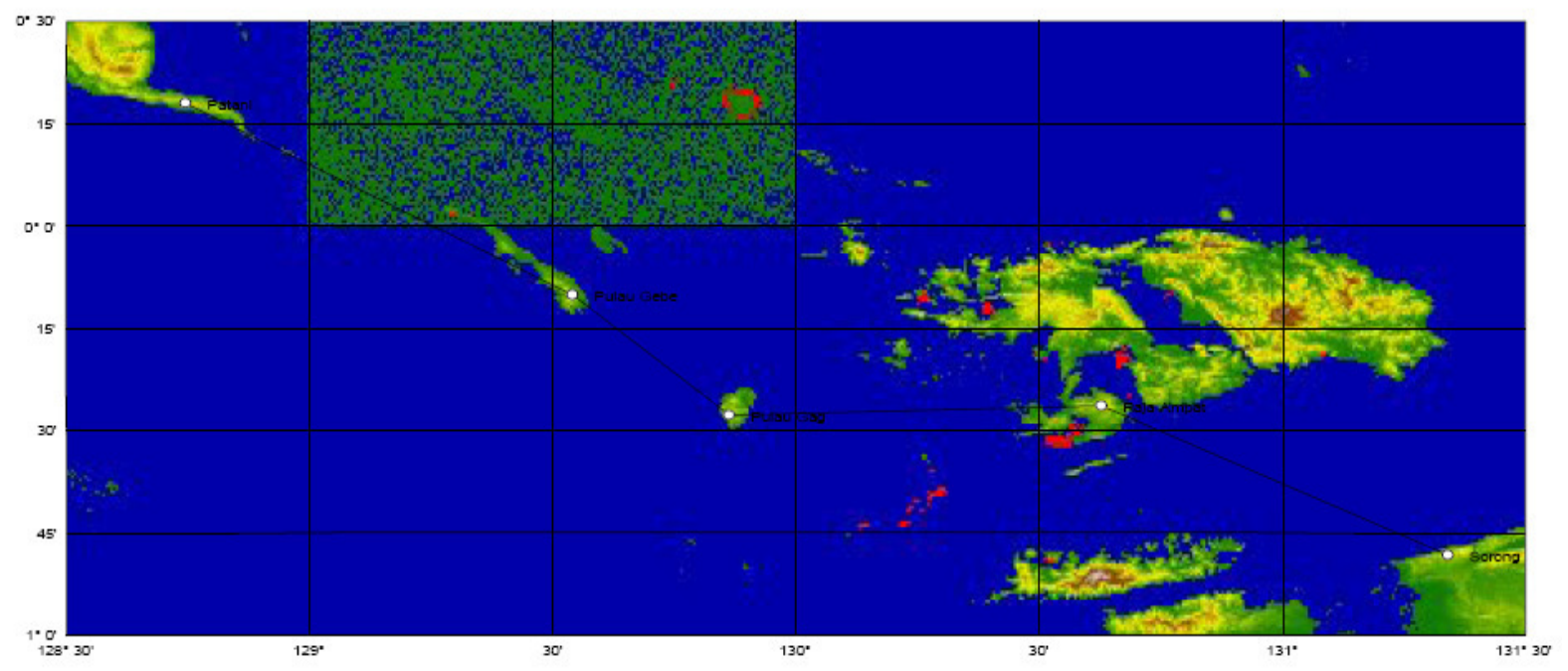

GAMBAR 1. Peta lokasi geografis pemasangan sistem radio komunikasi. 
TABEL 1. Data geografi untuk pemasangan

\begin{tabular}{|c|l|c|c|c|}
\hline No & Nama Site & Longitude & Latitude & $\begin{array}{c}\text { Elevasi } \\
\text { (mASL) }\end{array}$ \\
\hline 1 & Patani & $00^{\circ} 18^{\prime} 03.12^{\prime \prime} \mathrm{N}$ & $128^{\circ} 44^{\prime} 42.50^{\prime \prime} \mathrm{E}$ & 277 \\
\hline 2 & Pulau Gebe & $00^{\circ} 10^{\prime} 08.87^{\prime \prime} \mathrm{S}$ & $129^{\circ} 32^{\prime} 29.99^{\prime \prime} \mathrm{E}$ & 352 \\
\hline 3 & Pulau Gag & $00^{\circ} 27^{\prime} 40.75^{\prime \prime} \mathrm{S}$ & $129^{\circ} 51^{\prime} 50.47^{\prime \prime} \mathrm{E}$ & 297 \\
\hline 4 & Raja Ampat & $00^{\circ} 26^{\prime} 21.68^{\prime \prime} \mathrm{S}$ & $130^{\circ} 37^{\prime} 38.88^{\prime \prime} \mathrm{E}$ & 327 \\
\hline 5 & Sorong & $00^{\circ} 48^{\prime} 12.89^{\prime \prime} \mathrm{S}$ & $131^{\circ} 20^{\prime} 29.61^{\prime \prime} \mathrm{E}$ & 328 \\
\hline
\end{tabular}

TABEL 2. Data pulau dan jarak pemasangan

\begin{tabular}{|c|c|c|c|c|}
\hline No & Site A & Site B & Jarak $(\mathbf{K} \boldsymbol{m})$ & Keterangan \\
\hline 1 & Patani & Pulau Gebe & 102.78 & LOS \\
\hline 2 & Pulau Gebe & Pulau Gag & 48.29 & LOS \\
\hline 3 & Pulau Gag & Raja Ampat & 85.02 & LOS \\
\hline 4 & Raja Ampat & Sorong & 89.11 & LOS \\
\hline
\end{tabular}

\section{Konfigurasi Radio Link}

Pada SDH (Synchronous Digital Hierarcy) adalah teknologi yang memiliki sinkronisasi clock dan kapasitas yang tinggi. Pada perencanaan ini di asumsikan kebutuhan akan kapasitas kanal besar 5 x STM-1 (155 Mbps), maka radio yang akan digunakan teknologi SDH STM-1. Sedangkan frekuensi kerja yang digunakan adalah $5 \mathrm{GHz}$.

Path Profile Radio Link

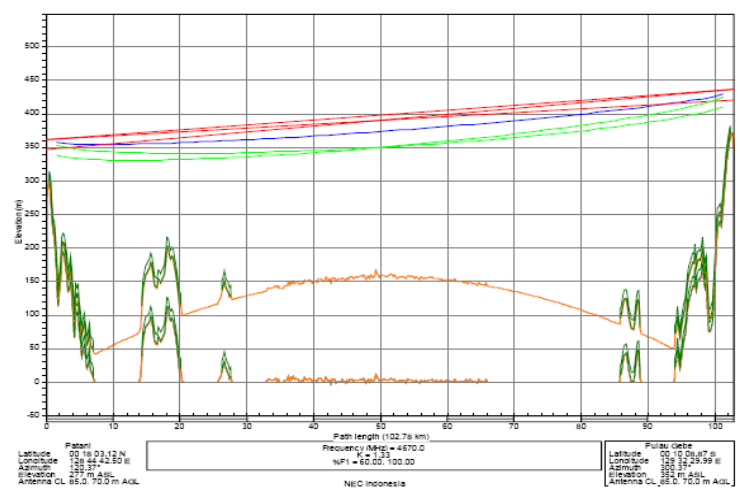

GAMBAR 2. Link Patani - Pulau Gebe

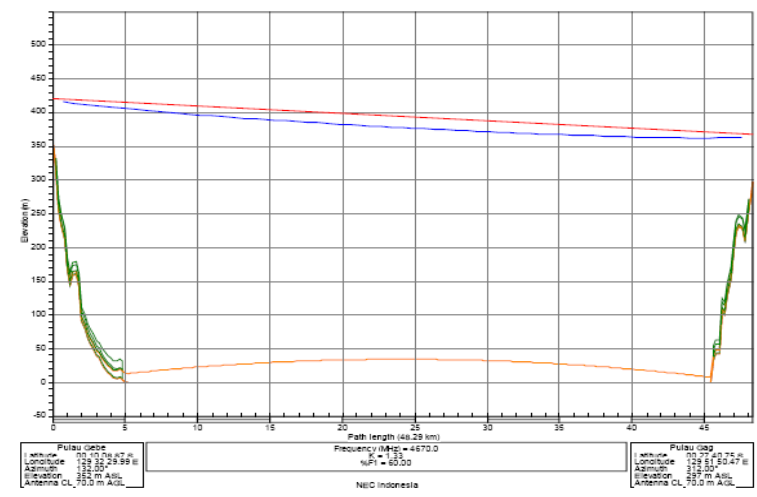

GAMBAR 3. Link Pulau Gebe - Pulau Gag 


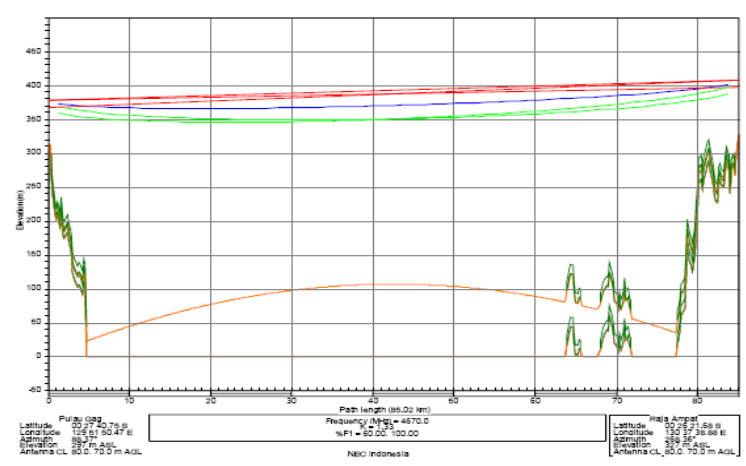

GAMBAR 4. Link Pulau Gag - Raja Ampat

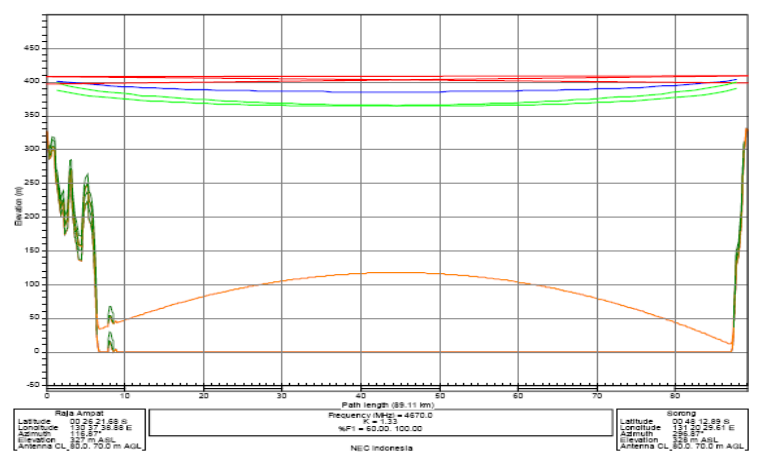

GAMBAR 5. Link Raja Ampat - Sorong

\section{ANALISA PERENCANAAN PADA RADIO LINK}

Berdasarkan data yang diperoleh akan dihitung secara teoritis perencanaan radio link dengan menggunakan microwave yang kemudian akan dianalisa hasil perencanaan jaringan transmisi tersebut. Adapun link yang akan dianalisa hanya diambil salah satu link saja, mengingat cara penghitungan link-link yang lain adalah sama sebagai berikut :

- Patani - Pulau Gebe

- Pulau Gebe - Pulau Gag

- Pulau Gag - Raja Ampat

- Raja Ampat - Sorong

Analisa perencanaan radio link yang telah disebutkan diatas mencakup beberapa hal sebagai berikut :

- Pembuatan Path Profile seperti perhitungan jari-jari Fresnell 1, perhitungan koreksi ketinggian dan perhitungan high clearence

- Perhitungan Power Link Budget meliputi perhitungan redaman, perhitungan level daya terima (RSL), dan perhitungan flat fade margin.

- Perhitungan Probabilitas Outage Tanpa Menggunakan Teknik Diversitas diantaranya perhitungan probabilitas non-selective outage, dan perhitungan probabilitas Selective outage

- Perhitungan Probabilitas Outage Dengan Menggunakan Teknik Diversitas

\section{Analisa Radio Link Patani - Pulau Gebe \\ Perhitungan Jari-jari Fresnell 1}

Perhitungan jari-jari fresnell 1 dapat dihitung pada lintasan gelombang radio yang melalui obstacle tertinggi sesuai dengan jarak $100,9 \mathrm{Km}(d l)$ dari Patani dan dari obstacle tertinggi ke Pulau Gebe $1,88 \mathrm{Km}(d 2)$ dengan kriteria $F 1=10,5 \mathrm{~m}$

\section{Perhitungan Koreksi Ketinggian}

Faktor koreksi terhadap kelengkungan bumi pada titik obstacle tertinggi sesuai dengan kriteria $h_{k}=11,2 \mathrm{~m}$ 


\section{Perhitungan High Clearence}

Kondisi lintasan dalam linkPatani - Pulau Gebe merupakan kontur perbukit dan laut dengan perkiraan ketinggian pepohonan 20 meter sehingga tinggi obstacle bertambah 20 meter. Maka high clearence di peroleh dengan kriteria $h_{c}=72,1 \mathrm{~m}$

\section{Perhitungan Power Link Budget}

\section{Perhitungan Redaman Transmisi}

Besarnya redaman transmisi pada suatu lintasan sesuai dengan persamaan sebagai berikut :

$$
L_{\text {tra }}=F S L+L_{b}+L f+L_{\text {rain }}+L_{\text {atm }}+L_{o}
$$

- Perhitungan Redaman Ruang Bebas (FSL), redaman ruang bebas diperoleh dengan persamaan :

$$
\begin{aligned}
& F S L=32,44+20 \log f(M H z)+20 \log d(\mathrm{~km}) \\
& F S L=146,06 d B
\end{aligned}
$$

- Readaman Brancing Circuit (Lb)

Redaman pada connector atau branching biasanya berkisar antara $0.01-0.05$ dB.Sehingga kita asumsikan Redaman Brancing Circuit $(L b)$ baik di Pemancar maupun di Penerima masing-masing sebesar $0.05 \mathrm{~dB}$.

- Redaman feeder $(L f)$

$\mathrm{L}_{\text {feeder }}=$ panjang feeder $(\mathrm{m}) / 100 \times 4.5 \mathrm{~dB} / \mathrm{m}(\mathrm{dB})$

diasumsikan panjang feeder $100 \mathrm{~m}$ sehingga

$\mathrm{L}_{\text {feeder }}=4.5 \mathrm{~dB}$

- Perhitungan redaman atmosfer $\left(L_{a t m}\right)$

$$
\begin{aligned}
& L_{a t m}=I \alpha \times \mathrm{d} d B \\
& L_{a t m}=0,0524 \times 102,78 \mathrm{~dB} \\
& L_{a t m}=5,39 \mathrm{~dB}
\end{aligned}
$$

- Perhitungan Redaman Hujan $\left(L_{\text {rain }}\right)$

Pada perhitungan redaman hujan agar dapat mengantisipasi keadaan terburuk diasumsikan antena berpolarisasi horizontal karena memberikan redaman maksimal dan hujan terjadi di sepanjang lintasan. Berdasarkan rekomendasi ITU-R P.8372 Indonesia termasuk ke dalam zona P dengan curah hujan $145 \mathrm{~mm} / \mathrm{h}$ :

$$
r=\frac{1}{1+d / d o}
$$

dimana :

$$
\begin{aligned}
& K: \text { Faktor iklim } \\
& R: \text { Curah hujan } \\
& \alpha: 1.332 \\
& \mathrm{~d}_{0}: 7.810
\end{aligned}
$$

Berdasarkan rekomendasi ITU-R P.530-8, nilai $C_{o}=3.5 ; C_{\text {lat }}=0 ; C_{i o n}=0 \mathrm{~dB}$. Untuk nilai $P_{L}$ dapat direkomendasikan ITU-R P.353 maka didapat $P_{L}=20 \%$. Perhitungan geoclimatic factor berdasarkan letak radio link yang termasuk dalam kategori coastal link with large size bodies of water sehingga di dapat perhitungan sebagai berikut :

$$
\begin{aligned}
K_{i} & =5.0 \times 10^{-7} \times 10^{0.1\left(C_{o}-C_{\text {lat }}-C_{\text {Lon }}\right)} P_{L}^{1.5} \\
K_{i} & =0.000019976
\end{aligned}
$$

dimana :

$$
\begin{aligned}
& \mathrm{PL}: \text { variabel iklim }(\%) \\
& \text { Co; } C_{\text {lat }} ; C_{\text {Lon }}: \text { tetapan }(d B)
\end{aligned}
$$

Maka akan diperoleh redaman transmisi adalah $L_{\text {trasmisi }}=158,04 d B$

- Perhitungan Gain Antena

Diameter antena yang digunakan pada link ini adalah 4,6 meter sehingga $\mathrm{G}=44,62 \mathrm{~dB}$ 
Gain total dari penjumlahan gain pada antena dan gain pada perangkat. Data dari perangkat di peroleh penguatan (gain) sebesar $33 \mathrm{dBm}$. Maka diperoleh gain totalnya adalah $G_{\text {total }}=$ $122.24 \mathrm{dBm}$

\section{Perhitungan Receiving Signal Level (RSL)}

Level sinyal yang di terima, di peroleh dari penguatan total (gain total) dengan redaman transmisi. Maka di peroleh level sinyal yang di terima adalah sebagai berikut :

$$
R S L=-35.8 \mathrm{dBm}
$$

\section{Perhitungan Flat Fading Margin (FFM)}

Flat Fading Margin di peroleh dari pengurangan RSL dengan level ambang terima ( $\left.R x_{\text {threshold }}\right)$. Dari daftar tabel diperoleh $R x_{\text {threshold }}$ sebesar-74.60 dBm, sehingga Flat Fading Margin sebesar :

$$
F F M=38.8 \mathrm{~dB}
$$

dimana :

$$
\begin{aligned}
& F F M \quad: \text { Flat Fading Margin } \\
& R S L \quad: \text { Level daya terima }(\mathrm{dBm}) \\
& R x_{\text {(threshold) }} \quad: \text { Level threshold dari thermal noise penerima }(\mathrm{dBm})
\end{aligned}
$$

\section{Perhitungan Probabilitas Outage Tanpa Menggunakan Teknik Diversitas}

Kemampuan operasional sistem transmisi dalam menyalurkan informasi di ukur dalam dua parameter, yaitu Probabilitas total outage dan Availability.Probabilitas total outage $\left(P_{t}\right)$ pada $\mathrm{BER}=10^{-6}$ yang telah ditetapkan oleh rekomendasi ITU-R F.634-3 untuk sistem radio dengan panjang lintasan $\mathrm{L} \leq 280 \mathrm{Km}$ adalah $P_{t} \leq 0,000448$

Availability sistem radio di atur oleh rekomendasi ITU-R F.634-3, dimana untuk sistem radio dengan panjang lintasan $\mathrm{L} \leq 280 \mathrm{Km}$ adalah $A V \geq 0,999252$

- Perhitungan Geoclimatic Factor

Berdasarkan rekomendasi ITU-R P.530-8, nilai $C_{o}=3.5 ; C_{l a t}=0 ; C_{i o n}=0 \mathrm{~dB}$. Untuk nilai $P_{L}$ dapat direkomendasikan ITU-R P.353 maka didapat $P_{L}=20 \%$.Perhitungan geoclimaticfactor berdasarkan letak radio link yang termasuk dalam kategori coastal link with large size bodies of water sehingga di dapat perhitungan sebagai berikut :

$$
\begin{aligned}
& K_{i}=5.0 \times 10^{-7} \times 10^{0.1\left(C_{o}-C_{\text {lat }}-C_{\text {Lon }}\right)} P_{L}^{1.5} \\
& K_{i}=0.000019976
\end{aligned}
$$

dimana :

$P_{L}$ : variabel iklim $(\%)$

$C_{o} ; \mathrm{C}_{\text {lat }} ; \mathrm{C}_{\text {Lon }}:$ tetapan $(d B)$

- Perhitungan Magnitudo Kemiringan Lintasan

$$
|\varepsilon p|=\frac{\left|h_{r}-h_{e}\right|}{d} \operatorname{mrad}
$$

dimana :

$h_{r} ; h_{e} \quad$ : Tinggi antena terhadap permukaan laut $(m)$

$d$ : Jarak radio link $(\mathrm{Km})$

$$
\begin{aligned}
& |\varepsilon p|=\frac{|348-420|}{102,78} \mathrm{mrad} \\
& |\varepsilon p|=0,7005 \mathrm{mrad}
\end{aligned}
$$

- Perhitungan $P_{W}$

$$
P w=K x d^{3.6} \times f^{0.89} \times(1+|\varepsilon p|)^{-1.4} \times 10^{-A / 10}
$$


dimana :

$$
P w=0.015832 \%
$$

$d \quad:$ Jarak radio link $(\mathrm{Km})$

$f \quad$ : Frekuensi $(G h z)$

$K \quad$ : Faktor iklim dan efek terrain

ep : Magnitudo dari kemiringan lintasan

A $\quad$ : Flat fading margin $(d B)$

\section{Perhitungan Probabilitas Outage Non-Selective}

$$
\begin{aligned}
P_{n s} & =\frac{P w}{100} \\
P_{n s} & =0.00015832
\end{aligned}
$$

- Perhitungan Multipath Occurance

$$
\begin{aligned}
& P o=\frac{P w}{100} \text { dengan } A=0(\%) . \\
& P o=121.8
\end{aligned}
$$

- Perhitungan Multipath Activity

$$
\begin{aligned}
& \eta=1-\exp \left(-0,2 \operatorname{xp}_{o}{ }^{0,75}\right) \\
& \eta=0,999
\end{aligned}
$$

- Perhitungan Mean Time Delay

$$
\begin{aligned}
\tau_{m} & =0,7\left(\frac{d}{50}\right)^{1,3} \\
\tau_{m} & =1,79 n s
\end{aligned}
$$

\section{Perhitungan Probabilitas Outage Selective}

$$
P s=2,15 \eta\left(W_{m} x 10^{-B m / 20} x \frac{\tau_{m}{ }^{2}}{\tau_{r} M}+W_{M N} x 10^{-B M N / 20} x \frac{\tau_{m}{ }^{2}}{\tau_{r} M N}\right)
$$

dimana :

$\eta=0,999 ; \tau_{m}=1,79 n s ; \mathrm{W}_{\mathrm{M}}=0.024 \mathrm{GHz} ; \mathrm{W}_{\mathrm{MN}}=0.024 \mathrm{GHz} ; \mathrm{B}_{\mathrm{M}}=32 ; \mathrm{B}_{\mathrm{MN}}=25 ; \tau_{r}$, $\mathrm{M}=\tau_{r}, \mathrm{MN}=6.3$;

dan

$\eta \quad$ : parameter multipath activity

$W_{m} \quad$ : minimum phase signature width

$W_{M N}:$ non minimum phase signature width

$B_{M} \quad$ : Minimum phase notch depth

$B_{M N}:$ Non minimum pahse notch depth

$\tau_{r} \quad$ : Peference time delay of signature curve

$\tau_{m} \quad$ : Mean time delay

$$
P s=2,15(0,999)\left(0,024 \times 10^{-32 / 20} x \frac{1,79^{2}}{6,3}+0,024 \times 10^{-25 / 20} \times \frac{1,79^{2}}{6,3}\right)
$$

$P s=0,0021178$

- Perhitungan Probabilitas Outage Total yaitu $P_{t}=P_{n s}+P_{s}$ sehingga diperoleh $P_{t}=0,002276$

- Perhitungan Availability adalah $A v=1$ - $P t$ sehingga diperoleh $A v=0,997723$

Perhitungan Probabilitas Outage Menggunakan TeknikSpace Diversitas

Probabilitas total outage $\left(P_{t}\right)$ pada BER $=10^{-6}$ yang telah ditetapkan oleh rekomendasi ITU-R F.634-3 untuk sistem radio dengan panjang lintasan $\mathrm{L} \leq 280 \mathrm{Km}$ adalah $P_{t} \leq 0,000448$ 
Availability sistem radio di atur oleh rekomendasi ITU-R F.634-3, dimana untuk sistem radio dengan panjang lintasan $\mathrm{L} \leq 280 \mathrm{Km}$ adalah $A V \geq 0,999252$.

- Perhitungan Probabilitas Outage Dengan Teknik Space Diversity.

$$
\begin{aligned}
& \left.I_{n s}=\mid 1-\exp \left(-3,34 \times 10^{-4} S^{0,87} f^{-0,12} d^{0,48} P_{o}^{-1,04}\right)\right] \times 10^{(A-V) / 10} \\
& V=\left|G_{1}-G_{2}\right| \\
& V=0 \\
& P o=\frac{P w x 10^{A / 10}}{100} \\
& P w=K x d^{3.6} \times f^{0.89} \times(1+|\varepsilon p|)^{-1.4} \times 10^{-A / 10}
\end{aligned}
$$

- Perhitungan Geoclimatic Factor

Berdasarkan rekomendasi ITU-R P.530-8, nilai $C_{o}=3.5 ; C_{l a t}=0 ; C_{i o n}=0 \mathrm{~dB}$. Untuk nilai $P_{L}$ direkomendasikan ITU-R P.353 maka didapat $P_{L}=20 \%$

$$
\begin{aligned}
& K_{i}=5.0 \times 10^{-7} \times 10^{0.1\left(C_{o}-C_{\text {lat }}-C_{\text {Lon }}\right)} P_{L}^{1.5} \\
& K_{i}=0.000019976
\end{aligned}
$$

dimana :

$$
\begin{aligned}
& P_{L}: \text { variabel iklim }(\%) \\
& C_{o} ; \mathrm{C}_{\text {lat }} ; \mathrm{C}_{\mathrm{Lon}}: \text { tetapan }(d B)
\end{aligned}
$$

- Perhitungan Magnitudo Kemiringan Lintasan

$$
\begin{aligned}
& |c p|=\frac{\left|h_{r}-h_{e}\right|}{d} \mathrm{mrad} \\
& |c p|=0,7005 \mathrm{mrad}
\end{aligned}
$$

dimana :

$h_{r} ; h_{e} \quad$ : Tinggi antena terhadap permukaan laut $(m)$

$d$ : Jarak radio link $(\mathrm{Km})$

- Perhitungan $P_{W}$ menggunakan persamaan $P w=K x d^{3.6} x f^{0.89} \times(1+|\varepsilon p|)^{-1.4} \times 10^{-A / 10}$ sehingga $P w=0.015832 \%$.

- Perhitungan Multipath Occurance dengan $P o=\frac{P w x 10^{A / 10}}{100}$, sehingga diperoleh $P o=121.78$

- Perhitungan Multipath Activity

$$
\begin{aligned}
& \eta=1-\exp \left(-0,2 x p_{o}{ }^{0,75}\right) \\
& \eta=0,999
\end{aligned}
$$

- Perhitungan Improvement Factor

$$
\begin{aligned}
& I_{n s}=\left\lfloor 1-\exp \left(-3,34 \times 10^{-4} S^{0,87} f^{-0,12} d^{0,48} P_{o}^{-1,04}\right)\right] \times 10^{(A-V) / 10} \text { sehingga diperoleh } \\
& I_{n s}=0.33458
\end{aligned}
$$

dimana :

$S \quad$ : Jarak pemisahan antar antena penerima $(m)$

$f \quad$ : Frekuensi $(\mathrm{GHz})$

$d \quad:$ Jarak radio link $(\mathrm{Km})$

$P_{o} \quad$ : Faktor multipath occurance

A : Flat fading margin

- Perhitungan Kuadrat Koefisien Korelasi Non-selective $K_{n s}{ }^{2}=1-\frac{I_{n s} x P_{n s}}{\eta}$ sehingga diperoleh $K_{n s}, S^{2}=0.999947$

dimana :

$I_{n s} \quad:$ Improvement factor 


\section{$P_{n s}:$ Probabilitas outage non-selective \\ $\eta$ : Parameter multipath activity}

- Perhitungan Koefisien Korelasi Relative Amplitude $r_{w}=1-0,6921\left(1-K_{n s}, S^{2}\right)^{1.034}$, untuk $K_{n s,} S^{2} \geq 0.26$ sehingga diperoleh $r_{w}=0,999973753$

- Perhitungan Kuadrat Koefisien Selective yaitu $K_{s}{ }^{2}=1-0,3957\left(1-r_{w}\right)^{0,5136}$ sehingga diperoleh $K_{s}{ }^{2}=0,99982436$

- Perhitungan Probabilitas Outage Non-Selective yaitu $P_{d n s}=\frac{P_{n s}}{I_{n s}} \quad$ sehingga diperoleh $P_{d n s}=0,000473190$

- Perhitungan Mean Time Delay $\tau_{m}=0,7\left(\frac{d}{50}\right)^{1,3}$ sehingga diperoleh $\tau_{m}=1,7861512 \mathrm{~ns}$ - Perhitungan Probabilitas Outage Selective yaitu $P_{d s}=\frac{P_{s}^{2}}{\eta\left(1-K_{s}^{2}\right)} \quad$ sehingga diperoleh $P_{d s}=0,000000000255$

- Perhitungan Probabilitas Outage Total yaitu $P_{d}=\left(P_{d n s}^{0,75}+P_{d s}^{0,75}\right)^{1,33}$ sehingga diperoleh $P_{d}=0,000048234$

- Perhitungan Availability yaitu $A v=1-P_{d}$ sehingga didapat $A v=0,99995176$

TABEL 1. Hasil Analisa Perhitungan Tanpa Menggunakan Diversitas

\begin{tabular}{|l|l|}
\hline Probabilitas Outage Total & 0,002276 \\
\hline Availability & 0,997723 \\
\hline ITU-R Outage Objective & 0,000448 \\
\hline ITU-R Availability & 0,999252 \\
\hline
\end{tabular}

TABEL 2. Hasil Analisa Perhitungan Menggunakan Teknik Diversitas

\begin{tabular}{|l|l|}
\hline Probabilitas Outage Total & 0,000048 \\
\hline Availability & 0,999951 \\
\hline ITU-R Outage Objective & 0,000448 \\
\hline ITU-R Availability & 0,999252 \\
\hline
\end{tabular}

TABEL 3. Data microwave worksheet Patani - Pulau Gebe 5GHz

\begin{tabular}{|c|c|c|c|}
\hline & Satuan & Patani & Pulau Gebe \\
\hline Elevation & $(\mathrm{m})$ & 277 & 352 \\
\hline Latitude & & $00^{\circ} 18^{\prime} 03.12^{\prime \prime} \mathrm{N}$ & $00^{\circ} 10^{\prime} 08.87^{\prime \prime} \mathrm{S}$ \\
\hline Longitude & & $128^{\circ} 44^{\prime} 42.50^{\prime \prime} \mathrm{E}$ & $129^{\circ} 32^{\prime} 29.99^{\prime \prime} \mathrm{E}$ \\
\hline True Azimuth & $\left({ }^{\circ}\right)$ & 120,37 & 300,37 \\
\hline Antenna height & $(\mathrm{m})$ & $85 \& 70$ & $85 \& 70$ \\
\hline Antenna Gain & $(\mathrm{dBi})$ & \multicolumn{2}{|c|}{44,62} \\
\hline Frequency & $(\mathrm{MHz})$ & \multicolumn{2}{|c|}{4670} \\
\hline Polarization & & \multicolumn{2}{|c|}{ Vertical } \\
\hline Path length & $(\mathrm{Km})$ & \multicolumn{2}{|c|}{102,78} \\
\hline Free space loss & $(\mathrm{dB})$ & \multicolumn{2}{|c|}{146,06} \\
\hline Atmospheric loss & $(\mathrm{dB})$ & \multicolumn{2}{|c|}{5,39} \\
\hline TX power & (watt) & \multicolumn{2}{|c|}{2} \\
\hline TX power & $(\mathrm{dBm})$ & \multicolumn{2}{|c|}{33} \\
\hline EIRP & $(\mathrm{dBm})$ & \multicolumn{2}{|c|}{77.62} \\
\hline RX thresholdcriteria & & \multicolumn{2}{|c|}{ BER $10^{-6}$} \\
\hline RX thershold level & $(\mathrm{dBm})$ & \multicolumn{2}{|c|}{$-74,6$} \\
\hline RX signal & $(\mathrm{dBm})$ & \multicolumn{2}{|c|}{$-35,8$} \\
\hline Geoclimatic factor & & \multicolumn{2}{|c|}{0,000372054} \\
\hline
\end{tabular}




\begin{tabular}{|l|c|c|}
\hline Occurance factor & & 121.8 \\
\hline Rain Rate & $(\mathrm{mm} / \mathrm{hr})$ & 145 \\
\hline Rain Attenuation & $(\mathrm{dB})$ & 2,04402396 \\
\hline Flat Fade Margin & $(\mathrm{dB})$ & 38.8 \\
\hline Path inclination & $(\mathrm{mrad})$ & 0,7005 \\
\hline
\end{tabular}

Berdasarkanhasil perhitungan di atas, harga probabilitas outage total dan availability sistem radio link Patani - Pulau Gebe harus menggunakan teknik diversitas agar memenuhi batas yang di rekomendasikan oleh ITU-R. agar link Patani - Pulau Gebe ini layak untuk di implementasikan menjadi backbone link

\section{Radio Link Pulau Gebe - Pulau Gag}

TABEL 4. Hasil Perhitungan Tanpa Menggunakan Diversitas

\begin{tabular}{|l|c|}
\hline Probabilitas Outage Total & 0,000177 \\
\hline Availability & 0,999827 \\
\hline ITU-R Outage Objective & 0.000448 \\
\hline ITU-R Availability & 0.999252 \\
\hline
\end{tabular}

TABEL 5. Hasil PerhitunganMenggunakan Teknik Diversitas

\begin{tabular}{|l|l|}
\hline Probabilitas Outage Total & 0,000035 \\
\hline Availability & 0.999964 \\
\hline ITU-R Outage Objective & 0.000448 \\
\hline ITU-R Availability & 0.999252 \\
\hline
\end{tabular}

TABEL 6. Data microwave worksheet Pulau Gebe - Pulau Gag 5GHz

\begin{tabular}{|c|c|c|c|}
\hline & Satuan & Pulau Gebe & Pulau Gag \\
\hline Elevation & $(\mathrm{m})$ & 352 & 297 \\
\hline Latitude & & $00^{\circ} 10^{\prime} 08.87^{\prime \prime} \mathrm{S}$ & $00^{\circ} 27^{\prime} 40.75^{\prime \prime} \mathrm{S}$ \\
\hline Longitude & & $129^{\circ} 32^{\prime} 29.99^{\prime \prime} \mathrm{E}$ & $129^{\circ} 51^{\prime} 50.47^{\prime \prime} \mathrm{E}$ \\
\hline True Azimuth & $\left({ }^{\circ}\right)$ & 132 & 312 \\
\hline Antenna height & $(\mathrm{m})$ & 70 & 70 \\
\hline Antenna Gain & $(\mathrm{dBi})$ & \multicolumn{2}{|c|}{44.62} \\
\hline Frequency & $(\mathrm{MHz})$ & \multicolumn{2}{|c|}{4670} \\
\hline Polarization & & \multicolumn{2}{|c|}{ Horizontal } \\
\hline Path length & $(\mathrm{Km})$ & \multicolumn{2}{|c|}{$\mathrm{c}$} \\
\hline Free space loss & $(\mathrm{dB})$ & \multicolumn{2}{|c|}{139.5} \\
\hline Atmospheric loss & $(\mathrm{dB})$ & \multicolumn{2}{|c|}{2,53} \\
\hline TX power & (watt) & \multicolumn{2}{|c|}{2} \\
\hline TX power & $(\mathrm{dBm})$ & \multicolumn{2}{|c|}{33} \\
\hline EIRP & $(\mathrm{dBm})$ & \multicolumn{2}{|c|}{77,62} \\
\hline RXthershold criteria & & \multicolumn{2}{|c|}{ BER $10^{-6}$} \\
\hline RX thershold level & $(\mathrm{dBm})$ & \multicolumn{2}{|c|}{-74.6} \\
\hline RX signal & $(\mathrm{dBm})$ & \multicolumn{2}{|c|}{-24.89} \\
\hline Geoclimatic factor & & \multicolumn{2}{|c|}{0.000372054} \\
\hline Occurance factor & & \multicolumn{2}{|c|}{6.45} \\
\hline Rain Rate & $(\mathrm{mm} / \mathrm{hr})$ & \multicolumn{2}{|c|}{145} \\
\hline Rain Attenuation & $(\mathrm{dB})$ & \multicolumn{2}{|c|}{1,89} \\
\hline Flat Fade Margin & $(\mathrm{dB})$ & \multicolumn{2}{|c|}{49,71} \\
\hline Path inclination & $(\mathrm{mrad})$ & \multicolumn{2}{|c|}{1,077} \\
\hline
\end{tabular}

\section{Radio Link Pulau Gag - Raja Ampat}

TABEL 7. Hasil Perhitungan Tanpa Menggunakan Diversitas

\begin{tabular}{|l|c|}
\hline Probabilitas Outage Total & 0,001796 \\
\hline Availability & 0.998203 \\
\hline ITU-R Outage Objective & 0.000448 \\
\hline ITU-R Availability & 0,999252 \\
\hline
\end{tabular}


TABEL 8. Hasil Perhitungan Menggunakan Teknik Diversitas

\begin{tabular}{|l|l|}
\hline Probabilitas Outage Total & 0,000126 \\
\hline Availability & 0.999873 \\
\hline ITU-R Outage Objective & 0.000448 \\
\hline ITU-R Availability & 0,999252 \\
\hline
\end{tabular}

TABEL 9. Data microwave worksheet Pulau Gag - Raja Ampat 5GHz

\begin{tabular}{|c|c|c|c|}
\hline & Satuan & Pulau Gag & Raja Ampat \\
\hline Elevation & $(\mathrm{m})$ & 297 & 327 \\
\hline Latitude & & $00^{\circ} 27^{\prime} 40.75^{\prime \prime} \mathrm{S}$ & $00^{\circ} 26^{\prime} 21.68^{\prime \prime} \mathrm{S}$ \\
\hline Longitude & & $129^{\circ} 51^{\prime} 50.47 ” \mathrm{E}$ & $130^{\circ} 37^{\prime} 38.88^{\prime \prime} \mathrm{E}$ \\
\hline True Azimuth & $\left({ }^{\circ}\right)$ & 88,37 & 268,36 \\
\hline Antenna height & $(\mathrm{m})$ & $80 \& 70$ & $80 \& 70$ \\
\hline Antenna Gain & $(\mathrm{dBi})$ & \multicolumn{2}{|c|}{44.62} \\
\hline Frequency & $(\mathrm{MHz})$ & \multicolumn{2}{|c|}{4670} \\
\hline Polarization & & \multicolumn{2}{|c|}{ Horizontal } \\
\hline Path length & $(\mathrm{Km})$ & \multicolumn{2}{|c|}{85,02} \\
\hline Free space loss & $(\mathrm{dB})$ & \multicolumn{2}{|c|}{144,43} \\
\hline Atmospheric loss & $(\mathrm{dB})$ & \multicolumn{2}{|c|}{4,46} \\
\hline TX power & (watt) & \multicolumn{2}{|c|}{31,6} \\
\hline TX power & $(\mathrm{dBm})$ & \multicolumn{2}{|c|}{33} \\
\hline EIRP & $(\mathrm{dBm})$ & \multicolumn{2}{|c|}{77,62} \\
\hline RXthershold criteria & & \multicolumn{2}{|c|}{ BER $10^{-6}$} \\
\hline RX thershold level & $(\mathrm{dBm})$ & \multicolumn{2}{|c|}{74,6} \\
\hline RX signal & $(\mathrm{dBm})$ & \multicolumn{2}{|c|}{$-32,31$} \\
\hline Geoclimatic factor & & \multicolumn{2}{|c|}{0,000372} \\
\hline Occurance factor & & \multicolumn{2}{|c|}{85,09} \\
\hline Rain Rate & $(\mathrm{mm} / \mathrm{hr})$ & \multicolumn{2}{|c|}{145} \\
\hline Rain Attenuation & $(\mathrm{dB})$ & \multicolumn{2}{|c|}{2,0130539} \\
\hline Flat Fade Margin & $(\mathrm{dB})$ & \multicolumn{2}{|c|}{42,29} \\
\hline Path inclination & $(\mathrm{mrad})$ & \multicolumn{2}{|c|}{0,35} \\
\hline
\end{tabular}

\section{Radio LinkRaja Ampat - Sorong}

TABEL 10. Hasil Perhitungan Tanpa Menggunakan Diversitas

\begin{tabular}{|l|c|}
\hline Probabilitas Outage Total & 0.001567 \\
\hline Availability & 0,998432 \\
\hline ITU-R Outage Objective & 0.000448 \\
\hline ITU-R Availability & 0,999252 \\
\hline
\end{tabular}

TABEL 11. Hasil PerhitunganMenggunakan Teknik Diversitas

\begin{tabular}{|l|c|}
\hline Probabilitas Outage Total & 0,000102 \\
\hline Availability & 0.999897 \\
\hline ITU-R Outage Objective & 0.000448 \\
\hline ITU-R Availability & 0,999252 \\
\hline
\end{tabular}

TABEL 12. Microwave Worksheet Raja Ampat - Sorong $5 \mathrm{GHz}$

\begin{tabular}{|l|c|c|c|}
\hline & Satuan & Raja Ampat & Sorong \\
\hline Elevation & $(\mathrm{m})$ & 327 & 328 \\
\hline Latitude & & $00^{\circ} 26^{\prime} 21.68^{\prime \prime} \mathrm{S}$ & $00^{\circ} 48^{\prime} 12.89^{\prime} \mathrm{S}$ \\
\hline Longitude & & $130^{\circ} 37^{\prime} 38.88^{\prime \prime} \mathrm{E}$ & $131^{\circ} 29^{\prime} 29.61^{\prime \prime} \mathrm{E}$ \\
\hline True Azimuth & $\left({ }^{\circ}\right)$ & 116,87 & 296,87 \\
\hline Antenna height & $(\mathrm{m})$ & 70 & 70 \\
\hline Antenna Gain & $(\mathrm{dBi})$ & \multicolumn{2}{|c|}{46.62} \\
\hline Frequency & $(\mathrm{MHz})$ & \multicolumn{2}{|c|}{ Horizontal } \\
\hline Polarization & \multicolumn{2}{|c|}{} \\
\hline
\end{tabular}




\begin{tabular}{|l|c|c|}
\hline Path length & $(\mathrm{Km})$ & 89,11 \\
\hline Free space loss & $(\mathrm{dB})$ & 144,83 \\
\hline Atmospheric loss & $(\mathrm{dB})$ & 4,67 \\
\hline TX power & $(\mathrm{watt})$ & 31,6 \\
\hline TX power & $(\mathrm{dBm})$ & 33 \\
\hline EIRP & $(\mathrm{dBm})$ & 77,62 \\
\hline RXthershold criteria & & $\mathrm{BER} 10^{-6}$ \\
\hline RX thershold level & $(\mathrm{dBm})$ & -74.6 \\
\hline RX signal & $(\mathrm{dBm})$ & $-32,93$ \\
\hline Geoclimatic factor & & 0,000372054 \\
\hline Occurance factor & & 148,32 \\
\hline Rain Rate & $(\mathrm{mm} / \mathrm{hr})$ & 145 \\
\hline Rain Attenuation & $(\mathrm{dB})$ & 2,02206337 \\
\hline Flat Fade Margin & $(\mathrm{dB})$ & 41,67 \\
\hline Path inclination & $(\mathrm{mrad})$ & 0,0244 \\
\hline
\end{tabular}

Berdasarkan hasil perhitungan di atas, harga probabilitas outage total dan availability sistem radio link Patani - Sorong memenuhi batas yang di rekomendasikan oleh ITU-R. sehingga link Patani - Sorong ini layak untuk di implementasikan menjadi backbone link.

\section{KESIMPULAN}

Berdasarkan apa yang telah ditulis dan menganalisa permasalahan, penulis memberikan kesimpulan seperti pada tabel 13. Kesimpulan tersebut adalah untuk meng-cover wilayah Patani - Sorong dibutuhkan 4 Hop.

TABEL 13. Kesimpulan hasil perhitungan Patani - Sorong 4 Hop

\begin{tabular}{|c|l|l|c|c|l|}
\hline No. & \multicolumn{1}{|c|}{ Site A } & \multicolumn{1}{|c|}{ Site B } & Pt & Av & \multicolumn{1}{c|}{ Keterangan } \\
\hline 1. & Patani & Pulau Gebe & 0,000048 & 0.999951 & LOS, menggunakan teknik diversitas \\
\hline 2. & Pulau Gebe & Pulau Gag & 0,000177 & 0,999827 & LOS, tanpa teknik diversitas \\
\hline 3. & Pulau Gag & Raja Ampat & 0,000126 & 0.999873 & LOS, menggunakan teknik diversitas \\
\hline 4. & Raja Ampat & Sorong & 0,000102 & 0.999897 & LOS, menggunakan teknik diversitas \\
\hline
\end{tabular}

Jarak yang berbeda pada setiap network, menyebabkan Received Signal Level (RSL) yang berbeda pula, dimana nilai RSL terbesar terdapat link Patani - Pulau Gebe $(35,8 \mathrm{dBm})$ dan terkecil pada link Pulau Gebe - Pulau Gag (-24,89 dBm).

\section{DAFTAR PUSTAKA}

[1] Bates, Regis J, Broadband Telecommunications Handbook, San Fransisco, 2002.

[2] ITU-T Recommendation, Reability and Availability of Analogue Cable Transmission, 2003.

[3] Roger L. Freeman. "Radio System Design For Telecommunication (1-100 Ghz)

[4] Roger L. Freeman. "Telecommunication Transmission Handbook, Edisi ke Empat.

[5] Rec. ITU-R P. 530-8, "Propagation Data And Prediction Method Required For The Design of Terresterial LINE OF SIGHT System".

[6] Rec. ITU-R P. 453, The Radio Refractive Index: ITS Formula and Refractivity Data".

[7] Rec. ITU-R P 634-3, Error Performance Objectives for Real Digital Radi-Relay Link Forming Part of High-Grade Circuit Within An Integrated Service Digital Network".

[8] Rec. ITU-R P. 676-3, “ Attenuation by Atmospheric Gases”.

[9] Rec. ITU-R F.1093, "Effect Of Multipath Propagation On The Design And Operation Of Line Of Sight Digital Radio-Relay Systems". 